\title{
THE RELATION BETWEEN CA 125, CECT ABDOMEN \& PELVIS AND HISTOPATHOLOGICAL FEATURES IN OVARIAN NEOPLASMS
}

\author{
Prakash S. S1, Charles Jude Antony², Ashwini B. G ${ }^{3}$
}

${ }_{1}^{1}$ Assistant Professor, Department of Surgical Oncology, K. R. Hospital, MMCRI, Mysore Karnataka, India.

2Postgraduate Student, Department of General Surgery, K. R. Hospital, MMCRI, Mysore Karnataka, India.

3Postgraduate Student, Department of General Surgery, K. R. Hospital, MMCRI, Mysore Karnataka, India.

\section{BACKGROUND}

ABSTRACT

CA 125 is a glycoprotein and a tumour marker mainly for epithelial ovarian neoplasms. It has potential utility across the spectrum: risk assessment, early detection, prognosis, monitoring and therapy. CT of the abdomen and pelvis is the first line imaging modality for staging, selecting treatment options and assessing disease response in ovarian cancer. The staging CT provides disease distribution, disease burden in the form of peritoneal metastasis, omental deposits or pelvic lymph nodes. Ovary is a complex structure and its neoplasms shows a wide spectrum of histological types and clinical behaviour.

The aim of this study was to evaluate the relation between CA 125, CECT abdomen \& pelvis and histopathological features in ovarian neoplasms.

\section{MATERIALS AND METHODS}

The present study is an observational study. The study was carried out between February 2018 to July 2018 in dept. of general surgery K. R. Hospital.

Inclusion Criteria - all cases of ovarian neoplasms who underwent imaging (CECT) with CA 125, followed by staging laparotomy during the course of study.

Exclusion Criteria - all cases of ovarian neoplasms who had received neo adjuvant chemotherapy.

\section{RESULTS}

Out of 80 patients, $24(30 \%)$ were benign and 56 (70\%) were malignant. In benign cases 66\% were having CA 125 values within normal limits and remaining 34\% were having elevated levels. In malignant cases, 7\% were having CA 125 within normal limits.

\section{CONCLUSION}

The results of the present study indicate remarkable diagnostic abilities of CA 125 and CECT abdomen and pelvis, in detection of extent of malignant spread of the ovarian disease. It is difficult to suggest a single investigative modality for evaluation of women with ovarian neoplasm. Patients with high level of CA 125 might have advanced stage ovarian neoplasms and are good candidates for neoadjuvant chemotherapy followed by surgery.

\section{KEY WORDS}

CA 125, Ovarian Neoplasms.

HOW TO CITE THIS ARTICLE: Prakash SS, Antony CJ, Ashwini BG. The relation between CA 125, CECT abdomen \& pelvis and histopathological features in ovarian neoplasms. J. Evolution Med. Dent. Sci. 2019;8(03):186-190, DOI: 10.14260/jemds/2019/41

\section{BACKGROUND}

Ovarian tumour is not a single entity but a complex wide spectrum of neoplasms involving a variety of histological tissues ranging from epithelial tissues, connective tissues, specialised hormone secreting cells to germinal and embryonal cells. The most common are epithelial tumours forming $80 \%$ of all tumours. Of all the malignant tumours $90 \%$ are epithelial in origin, $80 \%$ are primary in the ovary and $20 \%$ are secondary from the breast, git. Unfortunately, patients with ovarian tumours are often symptom-free for a long time and the symptoms are often nonspecific.

'Financial or Other Competing Interest': None.

Submission 09-11-2018, Peer Review 06-01-2019,

Acceptance 12-01-2019, Published 21-01-2019.

Corresponding Author:

Dr. Charles Jude Antony,

No. 190. I-Block,

Opposite Ganabharathi,

Kuvempu Nagar, Mysore-570023,

Karnataka, India.

E-mail: charlesjude227@gmail.com

DOI: $10.14260 /$ jemds $/ 2019 / 41$
By the time ovarian malignancy is established, about two thirds of these are already far advanced and the prognosis in such cases is unfavourable. An ovarian tumour in adolescent and post-menopausal women is more often malignant and in the reproductive age is mostly benign.[1]

\section{Symptoms}

- Bloating; abdominal distention or discomfort.

- Pressure effects on the bladder and rectum.

- Constipation.

- Vaginal bleeding.

- Indigestion and acid reflux.

- Shortness of breath.

- Tiredness.

- Weight loss.

- Early satiety.

Symptoms independently associated with the presence of ovarian cancer include pelvic and abdominal pain, increased abdominal size and bloating, and difficulty eating or feeling full.[2] Symptoms associated with later-stage disease include gastrointestinal symptoms such as nausea and vomiting, 
constipation, and diarrhoea. [3] Presentation with swelling of a leg due to venous thrombosis is not uncommon. Paraneoplastic syndromes due to tumour-mediated factors lead to various presentations.

Ovarian cancer is one of the leading cancers in Indian women and its more lethal than endometrial and cervical cancers. Owing to the lack of symptoms and early peritoneal dissemination, the tumour has spread outside the pelvis in approximately $70 \%$ of cases at the time of diagnosis. ${ }^{[4]}$ The stage at diagnosis is the most important prognostic factor. [5]

\section{Staging of Ovarian Cancer}

\section{FIGO staging system and corresponding TNM}

Stage I. Tumour confined to ovaries or fallopian tube(s)

\section{T1-N0-M0}

IA: tumour limited to one ovary (Capsule Intact) or fallopian tube; no tumour on ovarian or fallopian tube surface; no malignant cells in the ascites or peritoneal washings

\section{T1a-N0-M0}

IB: Tumour limited to both ovaries (Capsules Intact) or fallopian tubes; no tumour on ovarian or fallopian tube surface; no malignant cells in the ascites or peritoneal washings

\section{T1b-N0-M0}

IC: Tumour limited to one or both ovaries or fallopian tubes, with any of the following:

IC1: surgical spill.

\section{T1c1-N0-M0}

IC2: Capsule ruptured before surgery or tumour on ovarian or fallopian tube surface.

\section{T1c2-N0-M0}

IC3: Malignant cells in the ascites or peritoneal washings.

\section{T1c3-N0-M0}

Stage II. Tumour involves one or both ovaries or fallopian tubes with pelvic extension (below pelvic brim) or primary peritoneal cancer.

\section{T2-N0-M0}

IIA: Extension and/or implants on uterus and/or fallopian tubes and/or ovaries.

\section{T2a-NO-M0}

IIB: Extension to other pelvic intraperitoneal tissues.

\section{T2b-N0-M0}

Stage III. Tumour involves one or both ovaries or fallopian tubes, or primary peritoneal cancer, with cytologically or histologically confirmed spread to the peritoneum outside the pelvis and/or metastasis to the retroperitoneal lymph nodes.

\section{T1/T2-N1-M0}

IIIA1: Positive retroperitoneal lymph nodes only (Cytologically or histologically proven):

III A1 (i) Metastasis up to $10 \mathrm{~mm}$ in greatest dimension.

III A1 (ii) Metastasis more than $10 \mathrm{~mm}$ in greatest dimension.
III A2: microscopic extrapelvic (above the pelvic brim) peritoneal involvement with or without positive retroperitoneal lymph nodes.

\section{T3a2-N0/N1-MO}

IIIB: Macroscopic peritoneal metastasis beyond the pelvis up to $2 \mathrm{~cm}$ in greatest dimension, with or without metastasis to the retroperitoneal lymph nodes.

\section{T3b-N0/N1-M0}

IIIC: Macroscopic peritoneal metastasis beyond the pelvis more than $2 \mathrm{~cm}$ in greatest dimension, with or without metastasis to the retroperitoneal lymph nodes (Includes extension of tumour to capsule of liver and spleen without parenchymal involvement of either organ)

\section{T3c-N0/N1-M0}

Stage IV. Distant metastasis excluding peritoneal metastases Stage IVA: Pleural effusion with positive cytology

Stage IVB: Parenchymal metastases and metastases to extraabdominal organs (Including inguinal lymph nodes and lymph nodes outside of the abdominal cavity)

\section{Any T, any N, M1}

The 5 yr survival rates drops from 93\% in patients with localised disease to $28 \%$ in those with distant metastasis. Ca125 is the most frequently used biomarker for ovarian cancer detection.[6] CA 125 which has been found to be elevated in ovarian epithelial cancers is also found to be elevated in other cancers, including endometrial cancer, lung cancer, breast cancer and some git malignancies.[7] CECT of abdomen and pelvis is the standard imaging modality for preoperative imaging, staging at presentation and distinguishing between patients suitable for primary cytoreductive surgery and patients requiring neoadjuvant chemo prior to surgery. ${ }^{[8]}$

A-125 (cancer antigen 125, carcinoma antigen 125, or carbohydrate antigen 125) also known as mucin 16 or MUC16 is a protein that in humans is encoded by the MUC16 gene.[9] MUC16 is a member of the mucin family glycoproteins.[10]

\section{Structure}

Mucin 16 is a membrane associated mucin that possesses a single transmembrane domain.[11] A unique property of MUC16 is its large size. MUC16 is more than twice as long as MUC1 and MUC4 and contains about 22, 000 amino acids, making it the largest membrane-associated mucin. ${ }^{[12]}$ MUC16 is composed of three different domains:[13]

- An N-terminal domain.

- A tandem repeat domain.

- A C-terminal domain.

\section{Reference Range}

CA 125 is the tumour marker recommended for clinical use in the diagnosis and management of ovarian cancer. [14]

The normal values for CA 125 may vary slightly among individual laboratories. In most laboratories, the normal value is 0 to 35 units $/ \mathrm{ml}$. 


\section{Interpretation}

For women with ovarian cancer, CA 125 levels were found to correlate with tumour burden in $93 \%$ of cases.[15]

CA 125 levels may also be elevated in other malignancies, as well as in benign and physiologic conditions.[16]

\section{Monitoring Response to Therapy}

This study showed that CA 125 had 73\% sensitivity and 78\% specificity in predicting optimal cytoreduction, and other studies have yielded similar results.[17]

For women with ovarian cancer, the response to active treatment may be monitored using CA 125 , particularly if it was elevated at the time of diagnosis.[18] Using the criteria set forth by the Gynaecologic Cancer Intergroup (GCIG), a response is defined as a 50\% reduction in CA 125

\section{Detection of Recurrence}

CA 125 has also been used over the years to detect recurrence of ovarian cancer after primary therapy. Increasing levels of CA 125 precede the signs and symptoms of recurrence by 3-5 months in as many as $70 \%$ of cases.[19] The practice has been to monitor CA 125 every three months during the first years following primary treatment [20]

\section{Risk Factors for Ovarian Cancer}

Age - between 45 and 60. Nulliparous or of low parity. Women with previous PCOS or on tamoxifen. High calorie high fat diet. Genetic predisposition BRCA1 and BRCA2 genes. [21] Late menopause. Breast and git cancer. Prolonged HRT in menopausal women.

\section{Genetics}

\section{Hereditary Breast-Ovarian Cancer Syndrome}

A family history of ovarian cancer is a risk factor for ovarian cancer. People with hereditary non-polyposis colon cancer (Lynch syndrome), and those with BRCA-1 and BRCA-2 genetic abnormalities are at increased risk.

The major genetic risk factor for ovarian cancer is a mutation in BRCA1 or BRCA2 DNA mismatch repair genes, which is present in $10 \%$ of ovarian cancer cases. Only one allele need be mutated to place a person at high risk. The gene can be inherited through either the maternal or paternal line but has variable penetrance. [22],[23] Though mutations in these genes are usually associated with increased risk of breast cancer, they also carry a substantial lifetime risk of ovarian cancer, a risk that peaks in a person's 40 s and $50 \mathrm{~s}$. The lowest risk cited is $30 \%$ and the highest $60 \% .[24],[25]$ Mutations in BRCA1 have a lifetime risk of developing ovarian cancer of $15-45 \%$. Mutations in BRCA2 are less risky than those with BRCA1,[26] with a lifetime risk of $10 \%$ (lowest risk cited) to $40 \%$ (highest risk cited). On average, BRCAassociated cancers develop 15 years before their sporadic counterparts, because people who inherit the mutations on one copy of their gene only need one mutation to start the process of carcinogenesis, whereas people with two normal genes would need to acquire two mutations.

In the United States, five of 100 women with a firstdegree relative with ovarian cancer will eventually get ovarian cancer themselves, placing those with affected family members at triple the risk of women with unaffected family members. Seven of 100 women with two or more relatives with ovarian cancer will eventually get ovarian cancer. In general, 5-10\% of ovarian cancer cases have a genetic cause. BRCA mutations are associated with high-grade serous nonmucinous epithelial ovarian cancer.[25]

A strong family history of endometrial cancer, colon cancer, or other gastrointestinal cancers may indicate the presence of a syndrome known as hereditary nonpolyposis colorectal cancer (Also known as Lynch syndrome), which confers a higher risk for developing a number of cancers, including ovarian cancer.

\section{Aim}

To study the relation between CA 125, CECT abdomen \& pelvis and histopathological features in ovarian neoplasms.

\section{MATERIALS AND METHODS}

The present study is an observational study. The study was carried out between February 2018 to July 2018 in dept of general surgery K. R. Hospital

\section{Inclusion Criteria}

All cases of ovarian neoplasms who underwent imaging (CECT) with CA 125, followed by staging laparotomy during the course of study

\section{Exclusion Criteria}

All cases of ovarian neoplasms who had received neo adjuvant chemotherapy

\section{Statistical Analysis}

The data was collected and analysed using standard statistical chi - square test, $\mathrm{P}<0.05$ - statistically significant. Data was entered in Microsoft excel and analysis was done using SPSS version 22.

\section{RESULTS}

Out of 80 patients, $24(30 \%)$ were benign and 56(70\%) were malignant. In benign cases $66 \%$ were having CA 125 values with in normal limits and remaining 34\% were having elevated levels. In malignant cases $7 \%$ were having CA 125 within normal limits. Among cases with CA $125>600$ IU 50\% cases were having metastasis in CECT or HPE. In cases with CA 125 values $35-600 \mathrm{IU}, 37 \%$ were having metastatic disease. In the study there was significant association between CA 125 levels and type of tumour. Among those with benign tumour, majority had CA 125 levels $<35$ and among those with malignant lesions, majority had CA $125 \mathrm{~b} / \mathrm{w} 35$ to 600. In the study among those with Benign lesions, $66.67 \%$ had CA $125<35$ and $33.33 \%$ had CA $125>35$. Among those with Malignant lesions, $92.8 \%$ had CA $125>35$ and $7.2 \%$ had CA $125<35$. There was significant association between CA 125 levels and malignant lesions. CA $125>35$ had odds ratio of 26 for Malignant lesions. I.e. Those with CA $125>35$, had 26 times higher risk for malignancy. In the study among those with metastasis, $33.3 \%$ had CA $125>600$ and $66.7 \%$ had CA $125<600$. Among those without metastasis, $85.7 \%$ had CA $125<600$ and $14.3 \%$ had CA $125>600$. There was no significant difference in CA 125 and metastasis. 


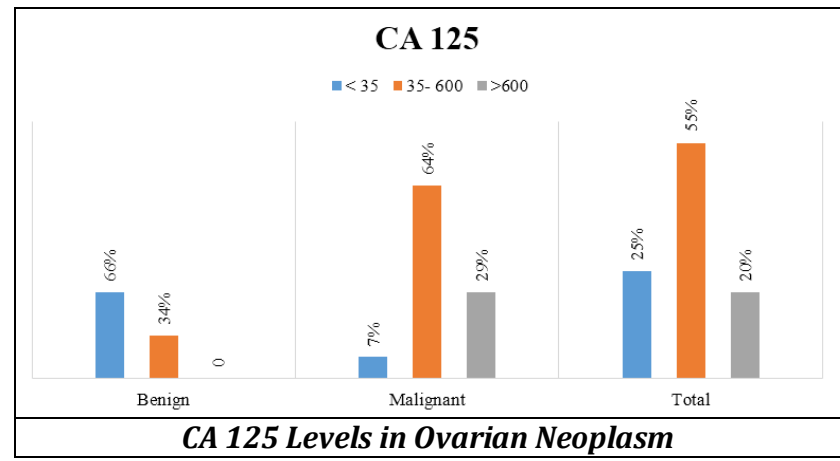

\begin{tabular}{|c|c|c|c|}
\hline CA 125 & Benign & Malignant & Total \\
\hline$<35$ & 16 & 4 & 20 \\
\hline $35-600$ & 8 & 36 & 44 \\
\hline$>600$ & 0 & 16 & 16 \\
\hline \multicolumn{2}{|c|}{ Table 1. CA 125 Levels in Ovarian Neoplasm } \\
\hline \multicolumn{3}{|c|}{ Chi Square $=33.59, \mathrm{df}=2, \mathrm{p}<0.001^{*}$} \\
\hline
\end{tabular}

In the study there was significant association between CA 125 levels and type of tumour. Among those with benign tumour, majority had CA 125 levels $<35$ and among those with malignant lesions, majority had CA 125 b/w 35 to 600 .

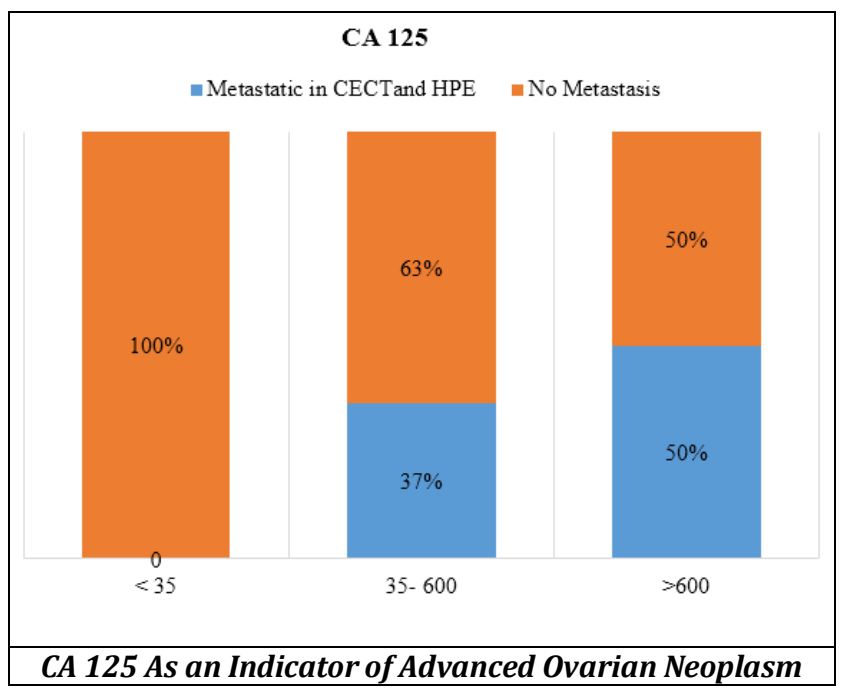

\begin{tabular}{|c|c|c|c|c|c|}
\hline \multirow{2}{*}{ CA 125 } & \multicolumn{2}{|c|}{$\begin{array}{c}\text { Metastatic in CECT } \\
\text { and HPE }\end{array}$} & \multicolumn{2}{|c|}{ No Metastasis } & \multirow{2}{*}{ Total } \\
\cline { 2 - 5 } & Count & $\%$ & Count & $\%$ & \\
\hline$<35$ & 0 & $0 \%$ & 20 & $35.7 \%$ & 20 \\
\hline $35-600$ & 16 & $66.67 \%$ & 28 & $50 \%$ & 44 \\
\hline$>600$ & 8 & $33.33 \%$ & 8 & $14.3 \%$ & 16 \\
\hline Table 2. CA 125 As an Indicator of Advanced Ovarian & Neoplasm \\
\hline \multicolumn{6}{|c|}{ Chi Square $=12.47, \mathrm{df}=2, \mathrm{p}=0.001 *$} \\
\hline
\end{tabular}

In the study among those with metastasis, $66.67 \%$ had CA 125 levels of 35 to 600 and $33.33 \%$ had $>600$ levels. Among those without Metastasis, $35.7 \%$ had CA $125<35$, 50\% had CA 125 b/w 35 to 600 and 14.3\% had CA 125 levels >600. There was significant association between CA 125 and Metastasis.

\begin{tabular}{|c|c|c|c|}
\hline Variable & Benign & Malignant & Odds Ratio \\
\hline CA $125<35$ & 16 & 4 & $\begin{array}{c}26(6.914, \\
97.77)\end{array}$ \\
\hline CA $125>35$ & 8 & 52 & Reference \\
\hline Table 3. Showing Odd S Ratio with Respect to Benign and \\
Malignant Status \\
\hline \multicolumn{3}{|c|}{ Chi Square $=31.75, \mathrm{df}=1, \mathrm{p}<0.001^{*}$} \\
\hline
\end{tabular}

In the study among those with Benign lesions, $66.67 \%$ had CA $125<35$ and 33.33\% had CA $125>35$. Among those with Malignant lesions, $92.8 \%$ had CA $125>35$ and $7.2 \%$ had CA $125<35$. There was significant association between CA 125 levels and malignant lesions.

CA $125>35$ had odds ratio of 26 for Malignant lesions. I.e. Those with CA $125>35$, had 26 times higher risk for malignancy.

\begin{tabular}{|c|c|c|c|}
\hline Variable & No Metastasis & Metastasis & Odds Ratio \\
\hline CA $125<600$ & 48 & 16 & $\begin{array}{c}3(0.9676, \\
9.301)\end{array}$ \\
\hline CA $125>600$ & 8 & 8 & Reference \\
\hline Table 4. Showing Odds Ratio with Respect to Metastatic \\
Status \\
\hline \multicolumn{3}{|c|}{ Chi Square $=3.81, \mathrm{df}=1, \mathrm{p}=0.0509$} \\
\hline
\end{tabular}

In the study among those with metastasis, $33.3 \%$ had CA $125>600$ and $66.7 \%$ had CA $125<600$. Among those without metastasis, $85.7 \%$ had CA $125<600$ and $14.3 \%$ had CA 125 $>600$. There was no significant difference in CA 125 and metastasis.

\section{DISCUSSION}

This study evaluated various modalities of investigation (CECT abdomen \&pelvis, CA 125) in ovarian neoplasms mainly to determine malignant nature, extent of local tumour spread and extra ovarian dissemination. The diagnostic abilities of each was analysed and correlated with one another, considering final HPE report as gold standard. The results indicated that combined parameters were superior in detection of ovarian malignancy and its spread than individual modalities taken independently. The utility of serum CA 125 monitoring in ovarian neoplasm patients can be considered in assessing response to chemotherapy and detecting early recurrence of the disease

\section{CONCLUSION}

The results of the present study indicate remarkable diagnostic abilities of CA 125 and CECT abdomen and pelvis in detection of extent of malignant spread of the ovarian disease. It is difficult to suggest a single investigative modality for evaluation of women with ovarian neoplasm. Patients with high level of CA 125 might have advanced stage ovarian neoplasms and are good candidates for neoadjuvant chemotherapy followed by surgery. Patients with normal levels of CA 125 or mild elevated CA 125 levels can be considered for cytoreductive surgery followed by adjuvant chemotherapies. In the study, among those with metastasis, $66.67 \%$ had CA 125 levels of 35 to 600 and $33.33 \%$ had $>600$ levels. Among those without metastasis, 35.7\% had CA 125 $<35,50 \%$ had CA $125 \mathrm{~b} / \mathrm{w} 35$ to 600 and $14.3 \%$ had CA 125 levels $>600$. There was significant association between $C A$ 125 and metastasis. 


\section{REFERENCES}

[1] Padubidri VG, Daftary SN. Howkins \& Bourne Shaw's textbook of gynaecology. $16^{\text {th }}$ edn. Elsevier 2015: p. 422-82.

[2] Shih M, Sokoll L, Chan DW. Ovarian cancer. In: Diamandis EP, Fritsche HA, Lilja H, eds. Tumour markers: physiology, pathobiology, technology and clinical applications. Washington DC: AACC Press 2002: p. 239-52.

[3] Davelaar EM, Van Kamp GJ, Verstraeten RA, et al. Comparison of seven immunoassays for the quantification of CA 125 antigen in serum. Clin Chem 1998;44(7):1417-22.

[4] Moideen N, Hebbar SS, Rai L, et al. Comparison of CA 125 , conventional ultrasound and CT imaging in diagnosis and staging of ovarian cancer correlated with surgico-pathological findings. Int J of Reprod Contracept Obstet Gynaecol 2014;3(4):924-30.

[5] Munkarah A, Chatterjee M, Tainsky MA. Update on ovarian cancer screening. Curr Opin Obstet Gynecol 2007;19(1):22-6.

[6] Johari-Ahar M, Rashidi MR, Barar J, et al. An ultrasensitive impedimetric immunosensor for detection of the serum oncomarker CA 125 in ovarian cancer patients. Nanoscale 2015;7(8):3768-79.

[7] Bast RC Jr, Xu FJ, Yu YH, et al. CA 125: the past and the future. International Journal of Biological Markers 1998;13(4):179-87.

[8] Sahdev A. CT in ovarian cancer staging: how to review and report with emphasis on abdomen and pelvic disease for surgical planning. Cancer Imaging 2016;16(1):19.

[9] Yin BW, Lloyd KO. Molecular cloning of the CA 125 ovarian cancer antigen: identification as a new mucin, MUC16. The Journal of Biological Chemistry 2001;276(29):27371-5.

[10] Duraisamy S, Ramasamy S, Kharbanda S, et al. Distinct evolution of the human carcinoma-associated transmembrane mucins, MUC1, MUC4 and MUC16. Gene 2006;373:28-34.

[11] Gipson IK. The ocular surface: the challenge to enable and protect vision: the Friedenwald lecture. Investigative Ophthalmology \& Visual Science 2007;48(10):4391-8.

[12] Gniewek P, Kolinski A. Coarse-grained modeling of mucus barrier properties. Biophysical Journal 2012;102(2):195-200.

[13] O'Brien TJ, Beard JB, Underwood LJ, et al. The CA 125 gene: an extracellular superstructure dominated by repeat sequences. Tumour Biology 2001;22(6):34866.
[14] Macuks R, Baidekalna I, Donina S. Comparison of different ovarian cancer detection algorithms. Eur J Gynaecol Oncol 2011;32(4):408-10.

[15] Bast RC Jr, Klug TL, St John E, et al. A radioimmunoassay using a monoclonal antibody to monitor the course of epithelial ovarian cancer. $\mathrm{N}$ Engl J Med 1983;309(15):883-7.

[16] Fularz M, Adamiak P, Czepczyński R, et al. Utility of PET/CT in the diagnosis of recurrent ovarian cancer depending on CA 125 serum level. Nuklearmedizin 2015;54(4):158-62.

[17] Rustin GJ, Van der Burg ME, Griffin CL, et al. Early versus delayed treatment of relapsed ovarian cancer (MRC OV05/EORTC 55955): a randomised trial. The Lancet 2010;376(9747):1155-63.

[18] Rustin GJ, Vergote I, Eisenhauer E, et al. Definitions for response and progression in ovarian cancer clinical trials incorporating RECIST 1.1 and CA 125 agreed by the Gynecological Cancer Intergroup (GCIG). Int J Gynecol Cancer 2011;21(2):419-23.

[19] Van der Berg ME, Lammes FB, Verweij J. The role of CA 125 in the early diagnosis of progressive disease in ovarian cancer. Ann Oncol 1990;1(4):301-2.

[20] Partridge EE, Barnes MN. Epithelial ovarian cancer: prevention, diagnosis and treatment. CA Cancer J Clin 1999;49(5):297-320.

[21] Jacobs I, Bast RC Jr. The CA 125 tumour-associated antigen: a review of the literature. Hum Reprod 1989;4(1):1-12.

[22] Seiden MV. Gynecologic malignancies. In: Longo DL, Kasper DL, Jameson JL, et al. Harrison's Principles of internal medicine. 18 $8^{\text {th }}$ edn. McGraw-Hill 2012.

[23] Hoffman BL, Schorge JO, Schaffer JI, et al. Epithelial ovarian cancer. Williams Gynecology. $2^{\text {nd }}$ edn. McGraw-Hill Publisher 2012: p. 853-78.

[24] National Comprehensive Cancer Network (NCCN) Clinical practice guidelines in oncology. Genetic/familial high risk assessment: breast and ovarian. Version 1. 2012. (Accessed September 6, 2012)

[25] Ovarian cancer. DynaMed. June 18, 2015. Archived from the original on June 21, 2015. https//dynamed.com/home/features/specialitycontent.

[26] CA125 definitions agreed by GCIG. http://www.gcig.igcs.org/CA125/respdef_nov2005.pd f (Accessed September 6, 2012) November 2005. 